\title{
Effectiveness of Video Assisted Teaching and Demonstration on Knowledge Regarding Personal Hygiene Among School Children
}

\author{
${ }^{1} \mathrm{M}$ Melvin David \\ Lecturer \\ Department of Community Health nursing \\ PES College of Nursing, Andhra Pradesh
}

\author{
${ }^{3}$ E Arulmozhi \\ Lecturer \\ Department of Community Health nursing \\ AVMC College of Nursing, Puducherry
}

\author{
${ }^{2}$ V Sujitra \\ Lecturer \\ Department of Community Health nursing \\ AVMC College of Nursing, Puducherry \\ ${ }^{4}$ Dr. M Navaneetha \\ Professor \\ Department of Community Health Nursing \\ College of Nursing, PIMS, Puducherry
}

Abstract:-

\section{$>$ Introduction}

The word hygiene is derived from the name of the ancient Greek goddess of healthful living-Hygeia. Hygiene refers to the practices associated with the protection of health and healthy living ${ }^{1}$. Poor health hygiene practices can lead to communicable diseases basically within developing countries. In Africa and Southeast Asia, $62 \%$ and $31 \%$ of all deaths are caused by infectious disease ${ }^{2}$.

School is place which not only provides education to children but also learning environment. The foundations of lifelong responsibility for the maintenance of personal hygiene are laid down in childhood, which is important for a healthy childhood, for a healthy adulthood, and for the development of positive values about health and the use of health services ${ }^{3}$. It's important to educate the students regarding personal hygiene in order to improve the quality of life of the children.

\section{$>$ Objectives}

1. To assess the general health status of the school children

2. To evaluate the effectiveness of video assisted teaching and demonstration on personal hygiene among school children.

\section{Methods}

A pre-experimental study was conducted in Government high school, Puducherry after obtaining prior permission. The seventy-three students of sixth standard were selected and general health assessment was done. The knowledge on personal hygiene were assessed using structured interview questionnaire. Collected data were entered in the Microsoft Excel 2013 and analyzed using Epi Info 7.0.
$>$ Results

The mean age of the school children are $10.8 \pm 0.6$ years, the mean weight was $29.8 \pm 6.7$ kilo grams, the mean height was $138.7 \pm 6.5$ centimeters. $8.2 \%$ and $6.9 \%$ of them had past medical and surgical history respectively. Only one girl attained menarche. Degree of malnutrition was calculated based on the weight for age by weech's formula and classified by Gomez classification. $36.9 \%$ of the children are having second degree malnutrition, $34.3 \%$ are having first degree malnutrition, $1.4 \%$ are having third degree malnutrition and $27.4 \%$ are maintaining normal nutritional status. $17.8 \%$ of the children are having vision problems. $12.3 \%$ are having dental carries. Two children are using spectacles. The pale conjunctiva was observed among 49.3\% of the children. $95.9 \%$ of them are immunized up to the age.

The knowledge on personal hygiene was assessed in both pre and post teaching. The mean pre teaching knowledge score was $8.13 \pm 2.4$ and post teaching knowledge score was $9.93 \pm 2.3$. the pre and post mean different was calculated with paired $t$-Test and the $t$ value is $\mathbf{- 8 . 6 9}(p=<0.001)$ reveals that the video assisted teaching and demonstration was effective.

\section{$>$ Conclusion}

This study concludes that the video assisted teaching and demonstration was effective in improving the knowledge on personal hygiene among school children. Improved knowledge may change the attitude of the schoolchildren and that may lead to a better hygienic practice. This study suggests to have regular teaching and training programme to improve the hygienic practices among school children.

Keywords:- School Children, Personal Hygiene, Video Assisted Teaching, Demonstration, Effectiveness. 


\section{INTRODUCTION}

The word hygiene is derived from the name of the ancient Greek goddess of healthful living-Hygeia. Hygiene refers to the practices associated with the protection of health and healthy living ${ }^{1}$. Poor health hygiene practices can lead to communicable diseases basically within developing countries. In Africa and Southeast Asia, $62 \%$ and $31 \%$ of all deaths are caused by infectious disease ${ }^{2}$.

School is place which not only provides education to children but also learning environment. The foundations of lifelong responsibility for the maintenance of personal hygiene are laid down in childhood, which is important for a healthy childhood, for a healthy adulthood, and for the development of positive values about health and the use of health services ${ }^{3}$. It's important to educate the students regarding personal hygiene in order to improve the quality of life of the children.

\section{MATERIALS AND METHODS}

A pre-experimental study was conducted in Government high school, Puducherry after obtaining prior permission. The seventy-three students of sixth standard were selected and general health assessment was done. The knowledge on personal hygiene were assessed using structured interview questionnaire. Collected data's were entered in the Microsoft Excel 2013 and analyzed using Epi Info 7.0

\section{RESULTS}

The study result shows that the mean age of the school children are $10.8 \pm 0.6$ years, the mean weight was $29.8 \pm$ 6.7 kilo grams, the mean height was $138.7 \pm 6.5$ centimeters. $8.2 \%$ and $6.9 \%$ of them had past medical and surgical history respectively. Only one girl attained menarche. Degree of malnutrition was calculated based on the weight for age by weech's formula and classified by Gomez classification. $36.9 \%$ of the children are having second degree malnutrition, $34.3 \%$ are having first degree malnutrition, $1.4 \%$ are having third degree malnutrition and $27.4 \%$ are maintaining normal nutritional status. $17.8 \%$ of the children are having vision problems. $12.3 \%$ are having dental carries. Two children are using spectacles. The pale conjunctiva was observed among $49.3 \%$ of the children. $95.9 \%$ of them are immunized upto the age.

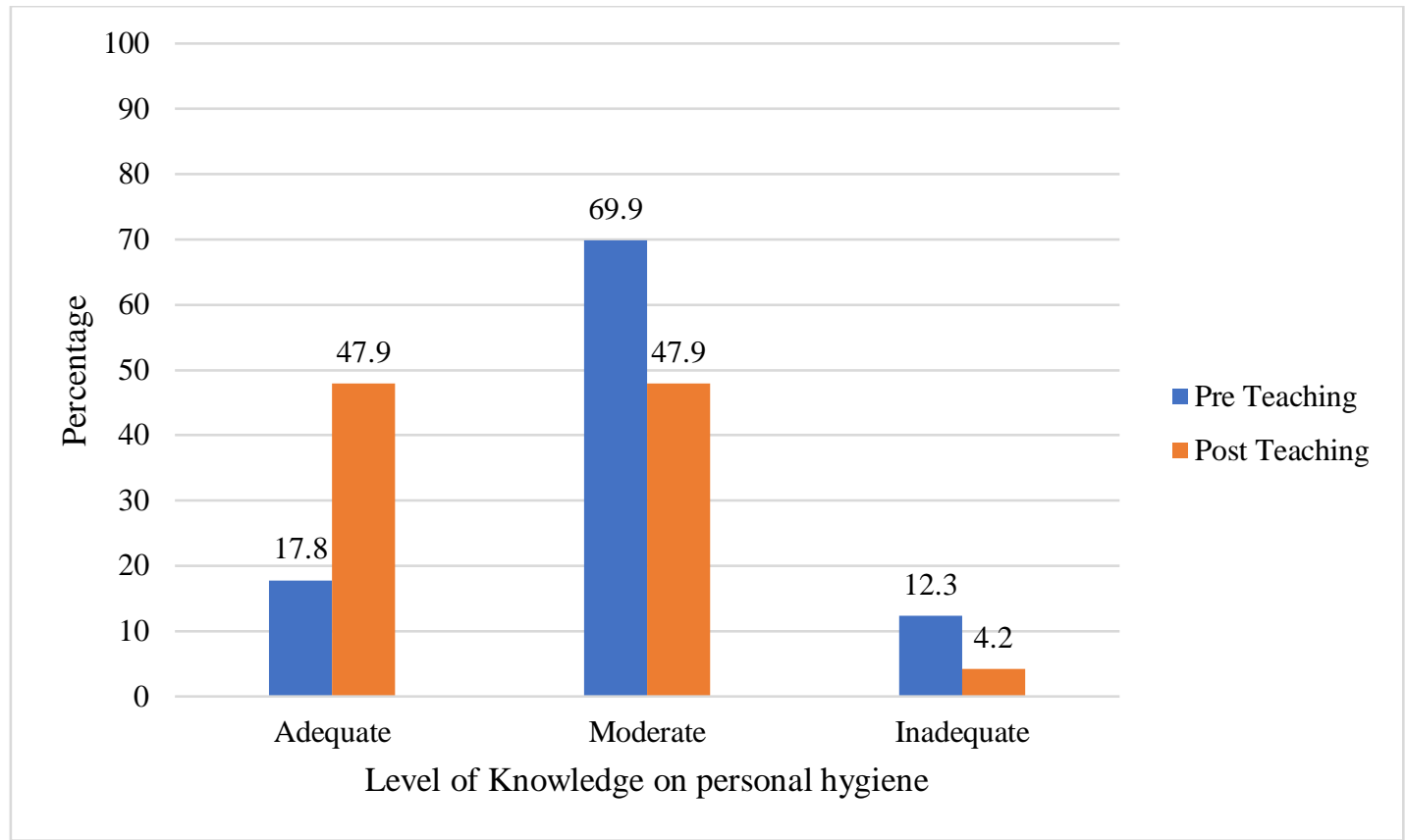

Fig 1:- Level of knowledge on personal hygiene among school children $\mathrm{N}=73$

The above figure shows that comparison of level of knowledge on personal hygiene between pre and post teaching among school children.

\begin{tabular}{|c|c|c|c|c|c|}
\hline S. No & Teaching & Mean & SD & t-Value & p- Value \\
\cline { 1 - 3 } & Pre-Teaching & 8.13 & 2.4 & \multirow{2}{*}{$\mathbf{- 8 . 6 9}$} & $<0.001$ \\
\hline
\end{tabular}

Table 1:- Effectiveness of video assisted teaching and demonstration on knowledge regarding personal hygiene among school children $\mathrm{N}=73$ 
The mean pre teaching knowledge score was $8.13 \pm$ 2.4 and post teaching knowledge score was $9.93 \pm 2.3$. the pre and post mean different was calculated with paired tTest and the $\mathrm{t}$-value is $-8.69(\mathrm{p}=<0.001)$ reveals that the video assisted teaching and demonstration was effective.

\section{DISCISSION}

The school going age is most important period in life where the children are learning a lot about life. The school environment provides variety of opportunities to develop once own. In this study we aimed to improve knowledge regarding personal hygiene among the school children. The students were trained with video assisted teaching and demonstration, the Post-teaching knowledge on personal hygiene was improved significantly among the school children.

\section{CONCLUSION}

This study concludes that the video assisted teaching and demonstration was effective in improving the knowledge on personal hygiene among school children. Improved knowledge may change the attitude of the schoolchildren and that may lead to a better hygienic practice. This study suggests to have regular teaching and training programme to improve the hygienic practices among school children.

\section{ACKNOWLEDGMENT}

We acknowledge the Dean, College of nursing, PIMS and Headmistress of Government high school, Puducherry for their constant support throughout the study period.

\section{REFERENCES}

[1]. Hygiene. [Last accessed on 2020 Jul 14]. Available from: https://www.answers.com/topic/hygiene

[2]. Curtis VA, Danquah LO, Aunger RV. Planned, motivated and habitual hygiene behaviour: An eleven country review. Health Educ Res. 2009;24:655-73.

[3]. Sachan B, Khatoon R, Khan M, Srivastava J. Impact of school health education program on personal hygiene among school children of Lucknow district. Journal of Family Medicine and Primary Care. 2017;6(1):97.

[4]. SARKAR M. Personal hygiene among primary school children livingin a slum of Kolkata, India [Internet]. PubMed Central (PMC). 2020. Available from: https://www.ncbi.nlm.nih.gov/pmc/articles/PMC47183 76

[5]. Rajbhandari A, Dhaubanjar R, GC K, Dahal M. Knowledge and practice of personal hygiene among secondary school students of grade nine and ten. Journal of Patan Academy of Health Sciences. 2018;5(2):107-113.

[6]. Ghanim M, Dash N, Abdullah B, Issa H, Albarazi R, Al Saheli Z. Knowledge and Practice of Personal Hygiene among Primary School Students in SharjahUAE. Journal of Health Science. 2016;6(5):67-73.
[7]. Gebreeyessus G, Adem D. Knowledge, Attitude, and Practice on Hygiene and Morbidity Status among Tertiary Students: The Case of Kotebe Metropolitan University, Addis Ababa, Ethiopia. Journal of Environmental and Public Health. 2018;2018:1-9. 